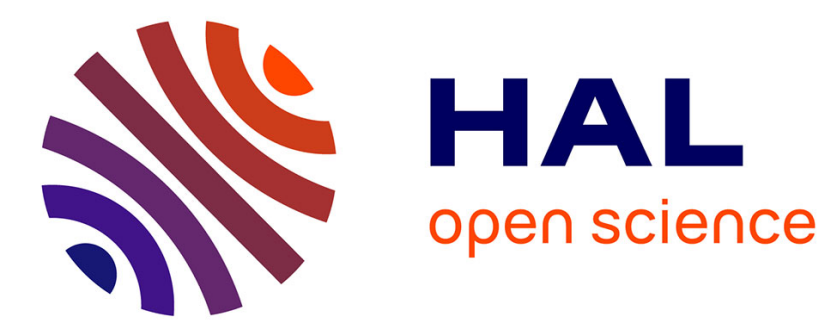

\title{
Rituels efficaces pour fonder ou déplacer un culte en Grèce ancienne
}

\author{
Anne Jacquemin
}

\section{To cite this version:}

Anne Jacquemin. Rituels efficaces pour fonder ou déplacer un culte en Grèce ancienne. Archimède: archéologie et histoire ancienne, 2020, 7, pp.62-75. halshs-02893154

\section{HAL Id: halshs-02893154 \\ https://shs.hal.science/halshs-02893154}

Submitted on 8 Jul 2020

HAL is a multi-disciplinary open access archive for the deposit and dissemination of scientific research documents, whether they are published or not. The documents may come from teaching and research institutions in France or abroad, or from public or private research centers.
L'archive ouverte pluridisciplinaire HAL, est destinée au dépôt et à la diffusion de documents scientifiques de niveau recherche, publiés ou non, émanant des établissements d'enseignement et de recherche français ou étrangers, des laboratoires publics ou privés. 


\section{ARCHIMĖDE N N 7}

DOSSIER THÉMATIQUE :

GESTES RITUELS. DE LA TRACE À L'INTERPRÉTATION

1 Sylvie DONNAT, Jean-Marie HUSSER

Le rite et ses traces. Perspectives méthodologiques

6 Marie AUGIER

Corps et objets interdits dans les sanctuaires (monde grec, ve av. - III ${ }^{\mathrm{e}}$ ap. J.-C.)

23 Claire CAMBERLEIN

Offrir l'antique à la divinité. L'exemple de l'adyton du sanctuaire de Vryokastro sur l'île de Kythnos (Cyclades)

37 Sylvie DONNAT

Les gestes rituels autour des papyrus-amulettes (Égypte, fin du II millénaire av. n. è.)

51 Jean-Marie HUSSER

Entre rituel, mémorial et littérature de propagande. À propos de deux textes ougaritiques au genre mal défini

62 Anne JACQUEMIN

Rituels efficaces pour fonder ou déplacer un culte en Grèce ancienne

76 Françoise LAROCHE-TRAUNECKER

Les rituels de construction des temples égyptiens. Gestes représentés sur les parois et actes attestés par des fouilles à Karnak

96 Denis MONNERIE

Circulation des objets et élaboration des relations dans les cérémonies du nord de la Kanaky Nouvelle-Calédonie

\section{ACTUALITÉ DE LA RECHERCHE}

294 VARIA 


\section{RITUELS EFFICACES POUR FONDER OU DÉPLACER UN CULTE EN GRĖCE ANCIENNE}

Anne JACQUEMIN

Professeur émérite d'histoire grecque

Université de Strasbourg

UMR 7044 Archimède

jacquemi@unistra.fr

\section{RÉSUMÉ}

La fondation d'un sanctuaire dans le monde grec supposait la transmission d'une sacralité qui avait lieu lors de l'installation de la divinité sous la forme d'une statue ou d'un autel. Les sources textuelles mettent l'accent sur le rôle dans ce processus d'objets appelés aphidrumata dont la nature variée a été souvent discutée. Le déplacement d'un sanctuaire deman-

MOTS-CLÉS

Aphidruma,

autel,

fondation,

Grèce,

sanctuaire,

sacrifice,

statue. dait un rituel du même type pour assurer la continuité de la sacralité. La confrontation des sources permet de revoir dans cette perspective le culte d'Athéna à Delphes.
In the Greek world the founding of a sanctuary required a transfer of holiness during the installation of the god/goddess as a statue or an altar. Primary sources emphasize the part aphidrumata take in the process. Nature of those is often matter of discussion. The moving out of a sanctuary to another place required the same type of ritual in order to have the sacrality going on. Confronting sources in this matter allows to have a new view on the Delphic cult of Athena.
KEYWORDS

Aphidruma altar, foundation, Greece, sanctuary, sacrifice, statue. 
Dans le monde romain, la consécration d'objets et la fondation de sanctuaires donnaient lieu à des processus bien connus qui comprenaient les étapes de dedicatio par laquelle le dédicant abandonnait la possession de ce qu'il donnait à la divinité, de consecratio où intervenaient des magistrats à fonction religieuse et d'inauguratio, qui concernait les seuls espaces sacrés. Le monde grec, en revanche, a laissé peu de traces de ses rituels [1]. En effet, les textes de la tradition manuscrite entrent rarement dans les détails, la documentation épigraphique ne s'intéresse guère aux aspects proprement religieux et I'interprétation des données archéologiques n'est pas toujours aisée.

C'est pourquoi sans doute les études qui ont porté depuis quelque vingt-cing ans sur la fondation des cultes dans le monde grec se sont le plus souvent intéressées aux mythes ou à la constitution des panthéons des cités, dans une perspective développée par Fr. de Polignac associant naissance des sanctuaires et naissance de la cité [2]. Les rituels accompagnant l'implantation d'un sanctuaire pouvaient certes être évoqués [3], mais ce point restait en marge, même dans le colloque organisé à Rome en 1995 par les Écoles françaises d'Athènes et de Rome [4]. Les travaux les plus importants sur les aspects matériels, ceux qui abordaient la question des objets servant à fonder un culte, l'ont fait généralement dans une perspective qui n'était pas directement en rapport avec la religion, puisque le point de départ de la recherche était une question de philologie ou de chronologie [5].

Nous nous proposons ici de mener une enquête

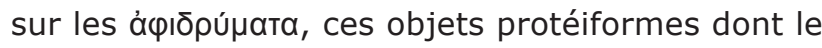
nom signifie simplement qu'ils sont ce à partir de quoi (ámó) on installe durablement dans un certain

[1] LAMBRINOUDAKIS 2005, p. 303-304.

[2] POLIGNAC 1995.

[3] Polignac 1997, p. 169-174; Pirenne-Delforge 2008, article sur lequel nous reviendrons.

[4] Agusta-Boularot, Huber \& Van Andriga 2017, p. 2 : un sujet intéressant, d'après les organisateurs, mais qui n'a pas vraiment passionné les participants, espace (ið̄úw) un culte. Nous verrons d'abord ce que nous pouvons savoir sur l'acte de fonder un culte, par le vocabulaire, par l'un des rares, sinon I'unique témoignage textuel sur ce geste et par les résultats des fouilles menées à Naxos par $\mathrm{V}$. Lambrinoudakis [6]. Nous reviendrons, à la lumière de ces données matérielles, sur deux exemples qui ont été fort débattus, celui de l'installation à Massalia d'un culte qui venait d'une autre cité que sa métropole Phocée, et celui de la demande adressée par les Ioniens d'Asie à Héliké en vue de la refondation d'un autel de Poséidon Hélikonios, dieu qui y était honoré. Nous retrouverons enfin ces objets dans les déplacements de cultes d'un point à un autre de l'espace communautaire, en nous intéressant tout particulièrement au cas de Delphes.

\section{RITUELS DE FONDATION}

Comme I'a bien montré V. Lambrinoudakis [7], les exemples grecs indubitables sont rares, à la fois parce que la documentation textuelle ne connaît pas le type d'écrit bien attesté en Orient et en Égypte où le souverain est personnellement attaché à l'acte de fondation sacrée, mais aussi parce que les fouilles ont rarement découvert les indices de tels rituels.

\section{LES MOTS POUR DIRE LA FONDATION}

Il existe en grec deux verbes signifiant « fonder », iठ $\rho u ́ \omega$ et $k$ тí $\omega$, qui peuvent s'employer avec comme complément les substantifs signifiant statue, autel, temple, fête... Cependant leurs sens originels font que seul le premier dit la fondation d'un culte dans une mention un peu plus développée (p. 71-73).

[5] BRUNEL 1953 ; MALKIN 1991 (interprétation

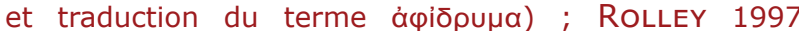
(chronologie de la fondation de Massalia).

[6] LAMBRINOUDAKIS 2002.

[7] LAMBRINOUDAKIS 2005, p. 306. 
toute sa réalité sacrée. Pendant longtemps, le sens premier et la formation d'íסpúw sont demeurés obscurs, même si le lien avec l'idée de siège était établi [8] ; mais une étude parue en 2000 a établi que le verbe était un présent factitif tiré du nom « siège » signifiant « faire un siège pour une divinité » [9]. Quant à $k T i \zeta \omega$, il est connu dès le grec mycénien avec le sens de « défricher » ou de « planter ». En grec alphabétique, dès Homère qui l'emploie pour des villes, des îles, il prend le sens de «fonder, installer, construire », puis celui $d^{\prime} \ll$ habiter » [10].

Le sens originel du verbe iঠoúw justifie son emploi en contexte cultuel, d'autant plus que l'un des noms de la statue, quand elle est « habitée » par la divi-

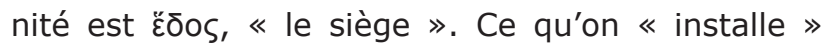
quand on fonde un culte, c'est bien la divinité sous une forme matérielle afin qu'elle puisse être présente en un lieu précis.

\section{L'IMPORTANCE DU TÉMOIGNAGE D'ARISTOPHANE}

Rares sont les témoignages textuels relatifs à des rites qui pourraient être ceux de l'instauration d'une statue de culte [11]. Dans sa communication du colloque Image et religion dans I'Antiquité gréco-romaine qui s'est tenu à Rome en 2003, V. Pirenne-Delforge [12] a étudié le « rite de l'instal-

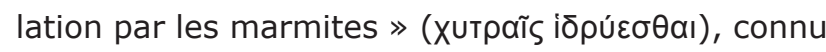
par Aristophane, mais aussi par des scholies et des gloses lexicographiques, dont la plus développée est celle de la Souda [13].

[8] Chantraine 2009, p. 439, s.u. iopúw (reproduisant l'édition première de 1968-1980).

[9] EgetMeyer 2009, renvoyant à Meier-Brügger 2000, p. 90-91.

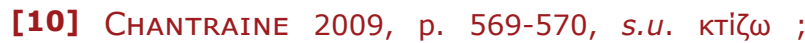
CASEVITZ 1985.

[11] Les études récentes (DonAHUE 1988 et 1998 ; SHEER 2000 ; PrOST 2009) ont bien montré que l'expression de « statue de culte», souvent employée par les auteurs modernes, n'a pas de sens pour les Grecs de l'Antiquité et qu'on ne saurait parler pour elle de « consécration » au sens où une cérémonie la ferait habiter par la divinité. Une même statue peut avoir à certains moments tout ce qu'il faut pour être le siège ( $\check{\delta} \delta \varsigma$ ) de la divinité, en étant

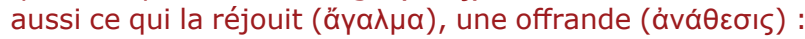
PROST 2009, p. 253-254.

[12] Pirenne-Delforge 2008. Voir aussi Hock 1905 p. 59-65.

[13] Aristophane, Paix, 923-942 : installation à Athènes d'Eiréné (la Paix) que Trygos et ses compagnons ont libérée de la caverne où la retenait Polémos ; Ploutos, 1191-1207 : installation de Ploutos (la Richesse) dans l'opisthodome de l'ancien temple d'Athéna, incendié par les Perses en 480, où était entreposée la fortune de
Aristophane suit de près le rituel avec ses offrandes alimentaires qui peuvent être végétales, sous forme de bouillie de légumineuses contenues dans des marmites, ou résulter du sacrifice sanglant de bœuf ou de mouton. À la différence de ce qui se passe lors

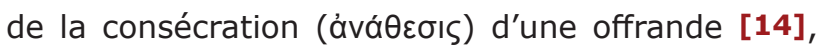
il s'agit ici de fonder un lieu où se dérouleront des

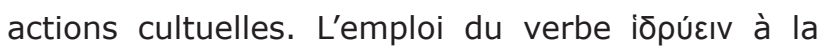
forme moyenne («fonder dans l'intérêt du sujet ») a également un sens fort. Comme le souligne G. Hock [15], le verbe s'emploie pour des temples, des autels, mais aussi pour les dieux et les héros accueillis par la communauté dans l'espace urbain ou la campagne.

\section{L'APPORT DES DÉCOUVERTES DE V. LAMBRINOUDAKIS À NAXOS}

Le caractère périssable de ces offrandes liées à l'installation d'une divinité explique sans doute pourquoi aucun vestige n'est attesté auprès d'un autel ou d'une base de statue. Les rares dépôts de fondation connus ont été en effet trouvés en rapport avec des édifices importants, temples ou trésors. Ils semblent s'expliquer par un souci d'assurer la solidité de la construction par le recours à des forces surnaturelles. C'est particulièrement net dans le cas des temples de Naxos, que ce soient les temples successifs de Dionysos à Hyria, le temple d'Apollon Délien dans l'île de Palatia ou le télestèrion de Déméter et Koré à Sangri [16]. On voit ici que le sacrifice, l'acte de culte le plus important dans le monde grec, est

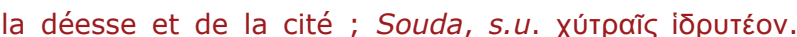
Comme les commentateurs l'ont fait remarquer, il ne s'agit pas de cultes officiels, puisque celui de la Paix ne semble pas attesté à Athènes avant les années 370 et que Ploutos, s'il est honoré à Éleusis, ne l'est point à Athènes. Cependant, dans ces fondations de culte imposées par l'intrigue des deux pièces, Aristophane ne peut que suivre les procédures en usage pour installer de nouveaux dieux à Athènes. Le poète comique n'invente pas et il est un témoin de poids.

[14] Il convient donc d'accorder toute sa valeur à la remarque de $\mathrm{J}$. Rudhardt sur les statues dites ávaӨńnaтa qui « à ce titre font l'objet d'une opération rituelle »(RUDHARDT 2001, p. 184), en se souvenant que la consécration qui fait passer l'objet d'une propriété humaine à une propriété divine ne fait pas de cette statue un opérateur du sacré nécessaire à l'accomplissement d'un sacrifice, ce que les Modernes appellent une « statue de culte ».

[15] Hock 1905, p. 4-5. La dédicace de Télémachos à Asclépios rappelle qu'il fut le premier à l'installer par des sacrifices divins commandés par la divinité (Inscriptiones

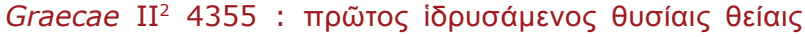
U்тroӨńkaıs).

[16] LAMBRINOUDAKIS 2002. 
aussi l'acte qui fonde un sanctuaire, que le lieu soit destiné à voir se dérouler d'autres immolations d'animaux ou non. Les dépôts de fondation contiennent des restes des cérémonies qui se sont déroulées à cette occasion, puisqu'ils conservent ce qui reste de la part des dieux - cendres et os calcinés -, mais aussi des éléments de vaisselle rituelle utilisée lors de la consommation du vin. Dans tous les cas, il ne s'agit pas des restes d'un sacrifice ordinaire associant dans la consommation de viande les dieux et les hommes, mais d'un rituel où I'animal, pour assurer la réussite du projet architectural, était entièrement consommé par les immortels.

Ces données archéologiques nous invitent à revenir sur la question des aphidrumata que nous abordons dans deux situations impliquant une transmission, celle de la fondation d'un sanctuaire-filiale et celle du déplacement d'un sanctuaire. Le premier cas est celui qui a suscité le plus de discussion à cause des sources textuelles en question, tandis que le second a moins intéressé. Des recherches menées dans le cadre d'un programme de l'École française d'Athènes dans le sanctuaire de Pronaia à Delphes [17] m’ont menée à reprendre la question par l'introduction d'un cas qui n'avait jamais été pris en compte.

\section{L'APHIDRUMA DANS LE CAS DE FONDATION DE NOUVEAUX SANCTUAIRES}

Les études consacrées aux aphidrumata sont fondées essentiellement sur deux exemples : le cas de l'Artémision de Massalia et celui de la refondation de l'autel de Poséidon Hélikonios au cap
Mycale par recours au sanctuaire censé être à I'origine du culte. Dans ces travaux, comme nous le

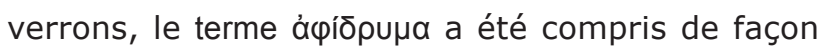
variée.

\section{L'ARTÉMIS ÉPHÉSIENNE DE MASSALIA}

La version la plus célèbre de la fondation de Massalia, que I'on trouve aussi bien dans la Constitution des Massaliètes d'Aristote que chez Justin I'abréviateur de Trogue-Pompée [18], est celle de la rencontre du Phocéen Prôtis, appelé aussi Euxénos, et de la Ségobrige Gyptis, thème qui fut fort exploité lors des fêtes du vingt-cinquième centenaire de la ville [19]. Dans ces récits, il n'est nullement question de fondation de cultes et de rituels liés à I'implantation des sanctuaires. Cependant Strabon, qui tire son information du philosopheethnographe Poseidonios d'Apamée, ainsi que d'Artémidore d'Éphèse [20], met l'accent sur les deux sanctuaires du promontoire (äkpa), celui d'Apollon Delphinios, commun à tous les Ioniens, et celui de l'Artémis d'Éphèse. Ce dernier lui paraît si digne de retenir l'attention qu'il en rapporte les conditions de l'introduction du culte, alors qu'il ne parle pas du sanctuaire d'Athéna, déesse principale de la métropole Phocée [21].

De façon curieuse, si I'on songe qu'Éphèse n'est point la métropole de la ville, Strabon semble utiliser alors le nécessaire rappel du statut d'ámoıкía de Massalia pour évoquer un transfert de culte d'Éphèse à Massalia, puis de Massalia à ses fondations. La personne qui assume le rôle de guide

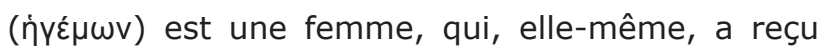
sa mission en songe d'Artémis [22]. Il est clair que cette femme n'est en rien l'équivalent féminin d'un

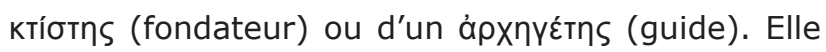

[17] Programme Marmaria dirigé par Sandrine Huber et Didier Laroche.

[18] Athénée, Le Banquet des sophistes, XIII, 576 (Aristote, fr. 503 Rose); Justin, Abrégé des histoires philippiques, XLIII, 3-4. La source première est sans doute I'historien Éphore.

[19] Voir I'affiche officielle avec une Gyptis portant la coiffure de la Dame d'Elche, un calendrier montrant Gyptis offrant à boire à Prôtis et des photographies de la cavalcade des 15 et 22 octobre 1899 : MoRELDeLETAILLE 1999. Quand à l'occasion des manifestations de « Marseille capitale européenne en 2013 » fut reconstruit I'un des bateaux de la Place Jules-Verne, il reçut le nom de Gyptis et effectua un certain nombre de voyages le long de la côte.

[20] Strabon, Géographie, IV, 1, $4=$ C 179. Voir LASSERRE 1966, p. 205.
[21] Strabon signale ailleurs (XIII, 1, $41=$ C 601) ce sanctuaire qui abritait une statue assise d'Athéna, comme celui de Phocée. D'après le texte de Justin (XLIII, 5, 6) évoquant l'apparition de la déesse en songe au chef gaulois Catumandus, il devait être situé sur I'acropole, l'actuelle Butte des Moulins, alors que les temples d'Apollon Delphinios et d'Artémis Éphésia sont à chercher sur la Butte Saint-Laurent (HERMARY, HESNARD \& TRÉZINY, p. 39). Deux faits témoignent de l'importance de cette déesse : les Massaliètes avaient offert à Delphes une grande statue de bronze d'Athéna (Pausanias, X, 8, 6 ) et certaines de leurs émissions monétaires avaient repris le type phocéen de la déesse casquée (BouvRY 2012, p. 47, fig. 27).

[22] Aucun parent n'intervient dans le récit. Le nom de la femme Aristarché, associant la notion d'excellence et celle de commandement, a incité parfois à voir en elle une figure mythique. Voir BOEDEKER 2017. 
doit embarquer avec les Phocéens, après avoir pris

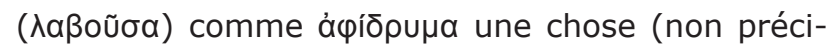

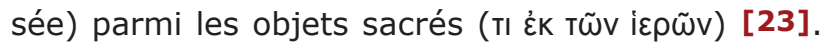
Ce transfert rituel a été associé tantôt à la fondation de la cité vers 600 [24], tantôt à une migration en 545 connue par Strabon citant Antiochos de Syracuse [25]. Les historiens qui ont développé cette dernière hypothèse ont distingué dans les Phocéens qui ont quitté leur cité pour échapper à la domination perse deux groupes, l'un, plus « politique », qui cherchait à fonder une nouvelle Phocée avec le mobilier sacré de la première [26], ce qui fut fait en Italie, à Élée, l'autre, plus « religieux » qui, après avoir recueilli à Éphèse de quoi fonder un culte qui donnât cohésion au groupe, se rendit à Massalia [27]. Cependant cette reconstitution du parcours du second groupe se heurte à la remarque d'Hérodote, selon laquelle ils furent

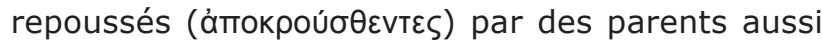
peu soucieux d'accueillir des concurrents que les habitants de Chios [28].

Comme l'a fait remarquer $\mathrm{Cl}$. Rolley, en associant la construction du sanctuaire de l'Artémis d'Éphèse et I'achèvement du processus de fondation (Tñs

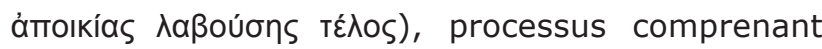
toutes les opérations qui s'étaient déroulées entre le départ de Phocée et l'implantation de la nouvelle cité, le texte de Strabon ne peut faire allusion qu'à la fondation de Massalia au tout début du $\mathrm{VI}^{\mathrm{e}}$ siècle. Il reste donc à expliquer ce détour par Éphèse que ceux qui se sont intéressés aux á laissé de côté, même si la documentation relative au Panionion [29] fournissait la clé de l'énigme. Les Phocéens sont partis avec ce qu'il fallait pour fonder les sanctuaires de la nouvelle cité, mais, si la majorité des cultes leur était propres, comme celui de leur Athéna Polias [30], ce n'était pas le cas de I'Artémis Éphésia. Aller chercher à Éphèse de quoi installer la déesse dans la nouvelle cité assurait la parfaite sacralité de l'implantation [31].

\section{L'AUTEL DE POSÉIDON HÉLICONIOS}

Un autre cas de retour au sanctuaire originel est en effet fourni par la refondation, dans les années 370, du sanctuaire de Poséidon Héliconios à son lieu originel du Panionion du cap Mycale ; au cours du $v^{e}$ siècle en effet les réunions des Ioniens d'Asie s'étaient tenues dans la région d'Éphèse. Cependant sans la catastrophe naturelle, un tremblement de terre suivi d'un tsunami, qui toucha le nord de I'Achaïe et tout particulièrement les cités d'Héliké et de Boura [32], l'épisode n'aurait sans doute pas eu l'écho qui fut le sien. Pour refonder I'autel de Poséidon Héliconios à sa place première, les Ioniens

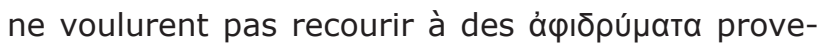
nant de l'autel de substitution du territoire éphésien. Ils décidèrent de s'adresser à la cité d'Héliké, alors achéenne, mais qui auparavant avait été ionienne, pour obtenir ce qui était nécessaire à la fondation.

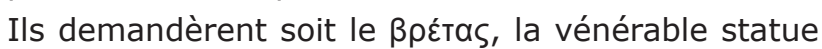

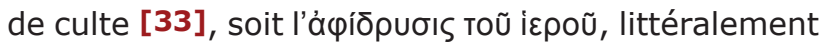
« la fondation du sanctuaire », ce qui donc le validait comme sanctuaire [34]. Si le koinon achéen avait bien accueilli la demande des Ioniens, la cité

[23] Fr. Lasserre traduit « en prenant avec elle un

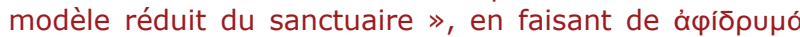
Tı le complément d'objet du participe et en traduisant le

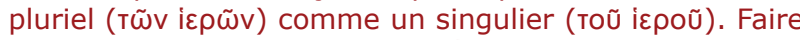

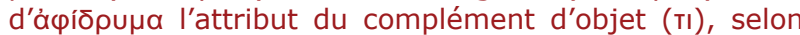
une tournure fréquente dans les dédicaces avec ámapxń,

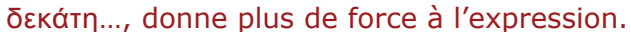

[24] Cette datation est confirmée aussi bien par des sources textuelles que par les données archéologiques: HeRmary, Hesnard \& TRÉZiny, p. 40.

[25] Strabon, VI, 1, $1=$ C252. Antiochos donne le nom (Créontiadès) du fondateur d'Élée après l'échec de I'installation à Massalia et en Corse. Hérodote ne parle que de la Corse et d'Alalia (I, 166-167).

[26] Hérodote, I, 164.

[27] BRUNEL 1948 (le premier à avoir clairement émis I'hypothèse); MALKIN 1987, p. 89-92 ; GRAS 1987 et 1995.

[28] Hérodote, I, 165. Quoique G. Vallet et Fr. Villard aient attiré I'attention sur ce point (VALLET \& VILLARD 1966, n. 57), rares furent ceux qui tinrent compte de cette donnée : voir AMPOLO 1994 et ROLLEY 1997, p. 36. [29] Voir infra.

[30] L'Apollon Delphinios dont Strabon dit qu'il est propre aux Ioniens avait donc également une composante locale.

[31] En rapprochant le cas d'Aristarché de ceux de la Parienne Cléoboia et du Troyen Anchise, Cl. Rolley a bien expliqué les raisons du choix de ces porteurs d'objets sacrés aux côtés du chef de l'expédition qui, lui, ne pouvait être qu'un guerrier (RoLLEY, 1997).

[32] Diodore, XV, 49 d'après Éphore ; Strabon, VIII, 7, 2, d'après Héraclide du Pont. Héliké fut longtemps cherchée par prospection sous-marine, y compris par le commandant Cousteau, avant d'être trouvée sous le bord de la mer entre les fleuves côtiers Sélinonte et Kérynitès : I'état des vestiges correspond à ce qui suit une destruction par tremblement de terre suivi d'un tsunami ; ultérieurement les ruines furent recouvertes par les eaux d'une lagune. Au même emplacement, un établissement du Bronze Ancien avait été détruit dans les mêmes conditions que la cité classique quelque deux mille ans plus tard : voir KATSONOPOULOU 2002.

[33] Strabon, VIII, 7, 2 = C 385.

[34] Ici la forme du nom d'action remplace celle du

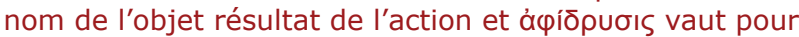

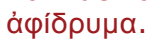


refusa. Dans la version de Diodore qui ne parle pas de la statue du dieu, mais simplement d'á le refus des citoyens d'Héliké est motivé par un dit ( $\lambda o ́ y ı$ ıv) selon lequel la cité connaîtrait un malheur si des Ioniens sacrifiaient sur l'autel de Poséidon. Comme les délégués venus d'Ionie, forts de l'approbation des autorités fédérales, sacrifiaient dans le sanctuaire avec l'intention de prendre les restes du sacrifice pour fonder, en le sacralisant ainsi, l'autel du cap Mycale, les gens d'Héliké les chassèrent et dispersèrent les vestiges du sacrifice, dans I'espoir, vain, de conjurer le sort [35]. C'est cet épisode qui

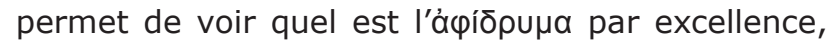
celui qui touche au plus près l'autel : ce sont les restes du sacrifice qui concentrent toute la force sacrée de l'acte et de la divinité et offrent donc la meilleure base pour fonder un culte. J. Brunel l'avait bien vu et son point de vue se serait imposé [36], sans I'autorité de L. Robert qui critiqua cette inter-

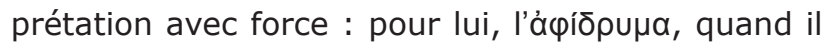
ne désigne pas un sanctuaire qui est une filiale ou une succursale d'un autre à partir duquel il a été installé, s'emploie pour une statue de culte faite à l'image d'une autre et qui sert au transfert de culte [37]. Il a donc fallu attendre l'article de $\mathrm{Cl}$.

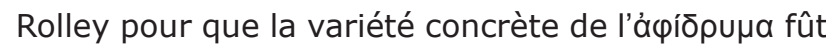
remise en lumière [38].

L'ironie de l'affaire d'Héliké a été bien dégagée par L. Prandi qui a analysé le rôle des intérêts spartiates dans la reprise des Panionia du cap Mycale et la disparition d'Héliké qui ne fut pas reconstruite, mais qui a aussi rappelé que, comme l'avait dit le spécialiste d'Homère Aristarque, Poséidon Héliconios est le dieu de l'Hélicon, et non d'Héliké [39]. Si les Ioniens avaient voulu faire les choses de la façon la plus pieuse, ils auraient dû s'adresser aux Béotiens, ce qui n'aurait pas été alors du goût des Spartiates.

[35] Ce qu'avaient fait en 396 les cavaliers envoyés par les béotarques, lorsque le roi de Sparte Agésilas avait voulu sacrifier à Aulis pour placer sa guerre contre les Perses dans la continuité de l'expédition d'Agamemnon contre Troie (Xénophon, Helléniques, III, 4, 3-4). L'action des Béotiens marqua durablement les esprits (Helléniques, III, 5, 5 et VII, 1, 34).

[36] BRUNEL 1953.

[37] ROBERT 1965, p. 119-126, particulièrement p. 123124. Voir aussi ROBERT 1977, p. 119-121 : un décret d'Argos en I'honneur du rhéteur Aristarchos d'Aigeai de Cilicie qui avait célébré la parenté entre les deux peuples et rappelé que Persée était venu en Cilicie тò тãs патрі́ou

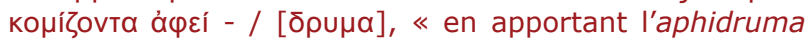
de la déesse ancestrale », la statue d'Athéna, ancestrale non seulement pour Persée, comme le pense L. Robert,

\section{AUTRES EXEMPLES DE FONDATION DE « FILIALE 》 CONNUS PAR LES SOURCES TEXTUELLES ET ARCHÉOLOGIQUES}

Les cas de l'Artémision de Massalia et du Panionion ont marqué les esprits et laissé des traces, mais de semblables installations divines se sont déroulées lors de la fondation de chaque ámoıкía (« colonie »), même si les vestiges en sont rares. Dans la Nékyia, inspirée en grande partie du chant XI de l'Odyssée, qu'il peignit dans la Lesché des Cnidiens à Delphes, Polygnote de Thasos inséra comme passagers de la barque de Charon Cléoboia, apportant dans un coffret les objets nécessaires à la fondation du culte de Déméter, et Tellis qui doit être le même individu que Télésiclès, le fondateur de la cité [40]. Cyrène présente un cas intéressant où les á à l'image de la déesse : dans le sanctuaire extra muros de Déméter et Coré furent trouvés six fragments de figurines antérieures d'une cinquantaine d'années à la fondation de la cité et de quelque soixante-quinze ans à I'implantation du lieu de culte [41]. Un point intéressant est que ce ne sont point des productions de Théra, mais de Rhodes de sorte que la question se pose de leur fonction réelle : ont-elles été apportées de Théra par des futurs citoyens de Cyrène dont les filles les auraient offertes aux Deux Déesses ? Ce serait alors des objets transmis à l'intérieur de la famille. Ou étaient-elles en lien direct avec un sanctuaire rhodien de Déméter et Coré dont elles auraient garanti la filiation ? En l'état actuel de la documentation il est impossible de trancher.

\section{L'APHIDRUMA DANS LE CAS DE DÉPLACEMENT DE SANCTUAIRE}

Après avoir abordé la question de la fondation de filiales ou de succursales de sanctuaires dans le

mais aussi pour Argos où elle avait son sanctuaire sur I'acropole de la Larisa.

[38] ROLLEY 1997.

[39] PRANDi 1989 et pour l'épiclèse p. 48-49. La confusion a pu être entretenue par le fait que les Ioniens avaient autrefois habité la terre devenue I'Achaïe.

[40] Pausanias, 28, 3. Pausanias, en faisant de Tellis le grand-père d'Archiloque, le distingue du fondateur de Thasos qui était son père. Sur le mythe des « missionnaires » qui auraient précédé les ámoıко।, voir RolLEY 1997, p. 38-39. Comme Aristarché, Cléoboia a accompagné l'expédition avec les objets nécessaires à I'installation d'une déesse.

[41] Il s'agit de quatre têtes, d'un torse acéphale et d'un haut de figurine; UHLENBROCK 2015. 
monde grec, il faut s'interroger sur le transfert de lieux de culte à l'intérieur d'un même espace. La différence majeure tient à ce qu'au terme du processus, dans un cas, il existe deux lieux de culte, et dans l'autre, un seul. De tels déplacements sont un phénomène assez bien connu dans la documentation textuelle, mais aussi archéologique.

\section{LE PROCESSUS CONNU PAR LES SOURCES TEXTUELLES}

Des inscriptions ont été découvertes qui concernent les deux phases du déplacement, la prise de décision résolue par la consultation d'un oracle et l'exécution avec l'attribution de fonds, la désignation de responsables... Ainsi une tablette trouvée à Dodone expose la demande de la polis des Chaones à Zeus et Diona à propos d'un éventuel déplacement du temple d'Athéna Polias [42]. Un décret de Tanagra de la fin du III $^{\mathrm{e}}$ siècle [43]

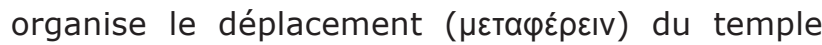
de Déméter et de Coré, après la consultation d'un oracle sur le choix entre trois possibilités - laisser le temple à sa place dans le proasteion [44], le reconstruire à Euameria, dans la chora, ou l'implanter à l'intérieur de l'enceinte. Fut élue pour trois ans, la durée prévue des travaux, une commission de trois citoyens âgés de plus de trente ans chargée avec les polémarques et l'architecte de choisir le terrain. Le texte s'intéresse ensuite à la mise en place d'une souscription qui ne s'adresse qu'aux femmes [45]. Le seul rite mentionné dans le texte est celui de l'accueil des déesses dans le temple urbain par une fête fleurie.

[42] LHÔTE 2006, n¹1 et QUANTIN 2007, notamment p. 180-182, pour l'identification de ce temple d'Athéna Polias à un édifice fouillé dans les années 1930 et alors interprété comme trésor : l'implantation a priori maladroite du bâtiment pourrait être un signe de son transfert.

[43] ReINACH $1899 ;$ KNOEPfler 1977 (pour la datation).

[44] Le lieu n'est pas précisé, mais le dieu consulté, I'Apollon de Delphes, ou plus vraisemblablement celui du Ptoion, très actif à l'époque hellénistique dans les affaires béotiennes, invite les Tanagréens à accueillir

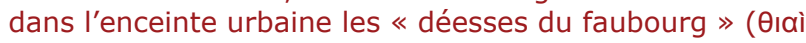

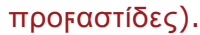

[45] Sur cette souscription singulière par le public visé, le faible montant de l'apport maximal, sur son but politique (renforcer la cohésion civique par le biais d'un culte réservé aux femmes et donner une impulsion à des travaux largement financé autrement), voir MIGEOTTE $1992, n^{\circ} 28$.

[46] Inscriptiones Graecae, XII, 8, 640 ; QUANTIN 2007 p. 184-185. Après avoir tout exécuté selon le contrat, il
Le déplacement au début du $\mathrm{II}^{\mathrm{e}}$ siècle av. J.-C. du temple d'Athéna à Péparéthos est connu par un décret en I'honneur d'un Athénien qui avait pris en

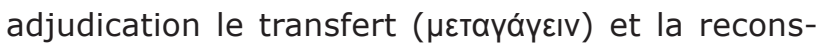

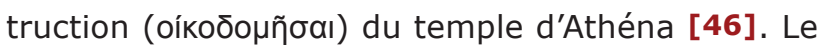
semblable destin du temple de Sôteira à Ikaros, l'actuelle île de Falaika au large du Koweit, est documenté par la copie d'une lettre royale rap-

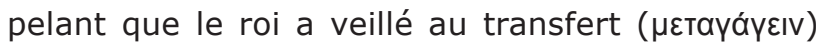
du sanctuaire de Sôteira, comme ses ancêtres l'avaient voulu, sans que cela eût pu se faire [47]. Dans les deux cas, aucune indication n'est donnée sur le motif du déplacement, ni sur le rituel qui a accompagné l'installation de la divinité dans son nouveau siège.

Un texte aurait pu, en revanche, nous informer sur le rituel d'installation de la divinité s'il était mieux conservé : il s'agit d'une loi de Cos trouvée à I'Asclépieion relative au bon accomplissement des cérémonies de purification conformément aux lois sacrées et ancestrales [48]. Dans la partie relative aux règles à suivre pour la fondation d'un autel à partir du transfert d'objets sacrés [49], il est dit qu'il faut sacrifier des animaux en conformité avec les usages, recueillir (les restes du sacrifice), après avoir éteint le feu de l'autel avec du vin ; le texte mentionne ensuite le feu perpétuel (áï̄oov) et de la terre de l'autel par lequel s'opérera le transfert et le fait de déplacer ( $\mu \varepsilon т \alpha \beta a ́ \lambda \lambda \varepsilon \varepsilon$ IV) cela sur (le nouvel autel) et de faire une purification tout autour avec un objet en or et des aspersions de graines (mav-

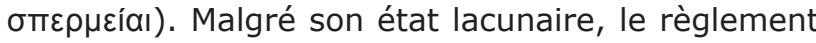
de Cos donne une idée de ce qu'était un rite de

s'était occupé avec l'architecte du transport de la base et de la statue et les avait installées à ses frais. Ce comportement lui valut la reconnaissance de la cité.

[47] Altheim \& Stiehl 1965. Le roi est simplement désigné par son titre royal et plusieurs souverains de la dynastie séleucide ont été proposés ; en l'état de la documentation, la seule condition à remplir est d'avoir eu des ancêtres maîtres de l'île, ce qui pourrait exclure Antiochos Ier qui n'aurait pu faire allusion qu'à son père.

[48] Inscriptiones Graecae, XII 4, 72, I. 58-63. Cette édition de 2010, due à KI. Hallof qui a revu le texte sur la pierre, a supprimé presque tous les compléments de HeRzog $1928, n^{\circ} 8$ p. 20-28, repris par SokolowSKI $1969, n^{\circ} 154$. Deux copies de cette loi votée vers 240 avaient été consacrées, l'une dans un sanctuaire de Déméter, I'autre dans I'Asclépieion.

[49] Le verbe $\mu \varepsilon т а \varphi \varepsilon \dot{p \varepsilon ı v ~ e s t ~ p r e ́ s e n t ~ d e u x ~ f o i s ~ a u x ~ l i g n e s ~}$ 60-61 ; il est en partie restitué la première fois, mais intégralement conservé la seconde. Sur les sanctuaires de Déméter à Cos, voir PAUL 2013, p. 72-79, 244-247 et 252-254. 
fondation d'un culte et confirme l'importance du lien assuré par les restes sacrificiels [50].

Pausanias évoque deux transferts de cultes de Calydon à Patras à l'époque augustéenne, ceux des cultes de Dionysos et d'Artémis Laphria, mentionnant dans les deux cas le déplacement de la statue, mais ne disant rien des modalités proprement dites de l'installation à Patras de la divinité [51].

\section{L'APPORT DE L'ARCHÉOLOGIE}

\section{Temples voyageurs et déplacement de petits sanctuaires}

L'archéologie révèle des transferts de culte par des indices positifs (implantation en un lieu d'une construction venant d'ailleurs) ou négatifs (découverte de vestiges recouverts par une construction ultérieure) ; ces derniers sont plus difficiles à interpréter, puisqu'ils ne sont pas toujours en liaison avec des éléments témoignant de l'existence en un autre lieu de ces mêmes cultes.

La première situation est illustrée par ce qui a été désigné par l'expression de « temples voyageurs » dont les exemples les plus frappants ont été identifiés à l'agora d'Athènes avec le temple d'Arès, le temple est et le temple sud-ouest [52] : il s'agit dans le premier cas d'un édifice entièrement déplacé pierre par pierre [53] ; dans les deux autres, de colonnes du temple d'Athéna à Sounion et d'un édifice inachevé de Thorikos. Cependant l'idée même de déplacement de temple à l'époque impériale a été remise en cause [54] et S. et Fr. Quantin ont montré que la notion de « temple voyageur » n'a aucun sens pour un Grec de l'Antiquité qui ne conçoit pas le temple comme démontable [55].

[50] R. Herzog avait restitué les termes de xútpaı pour les récipients utilisés lors du transfert et à ce qu'on recueillait sur l'autel : il ne reste rien du premier et seulement I'alpha final du second.

[51] Pausanias, VII, 21, 1 - sanctuaire de Dionysos Calydonios ; 18, 8-13 : sanctuaire d'Artémis Laphria, statue chryséléphantine de la déesse en chasseresse et rituel sacrificiel très particulier. Les deux sanctuaires n'ont pas été identifiés, mais le second se trouvait sur l'acropole. Si Pausanias parle d'un abandon du site de Calydon par sa population déplacée à Nicopolis, les fouilles ont montré que le sanctuaire d'Artémis Laphria à Calydon a été fréquenté jusqu'au III ${ }^{\mathrm{e}}$ siècle (VIKATOU \& SeRATI 2013, p. 14 et 18-19).

[52] CAMP 1989, p. 208-210.

[53] Comme l'édifice est très vraisemblablement le temple d'Arès vu par Pausanias ( $I, 8,4)$, il a été mis en relation avec le sanctuaire d'Arès et d'Athéna Areia à
Dans le cas du théâtre d'Argos, qui ne pouvait guère être bâti à un autre emplacement, la construction a entraîné au III ${ }^{\mathrm{e}}$ siècle le déplacement de petits sanctuaires qui devaient se trouver sur la pente : ainsi, dans la parodos nord, fut élevé un autel à deux compartiments qui fut abandonné dès le $\mathrm{II}^{\mathrm{e}}$ siècle; la parodos sud, elle, conserve, grâce à une borne et à un relief, le souvenir des cultes de Zeus Eubouleus, divinité associée à la Déméter éleusinienne et des Dioscures [56].

\section{Proposition d'utilisation de la clé du déplacement d'un lieu de culte dans le cas du sanctuaire de Pronaia à Delphes}

Les indices négatifs pourraient se révéler plus intéressants, mais il faudrait avoir la preuve que le culte qui était célébré dans le sanctuaire dont les vestiges sont découverts sous une construction s'est poursuivi ailleurs, ce qui n'est pas toujours aisé à savoir. Le cas de Delphes dans la seconde moitié $\mathrm{du} \mathrm{vI}^{\mathrm{e}}$ siècle, un cas qui a peu retenu l'attention, pourrait se révéler d'un grand intérêt [57]. Après l'incendie du temple en 548, I'Amphictionie décida une reconstruction du temple en plus grand et, pour ce faire, entreprit de remodeler entièrement le sanctuaire pour créer une grande terrasse en mesure d'accueillir l'édifice. Le projet provoqua I'ensevelissement d'un certain nombre d'édifices, la destruction d'autres bâtiments [58] (fig. 1). Les blocs des élévations des monuments démontés ont été remployés dans l'élévation du mur dit polygonal qui dresse sur une fondation en appareil polygonal quinze assises d'appareil isodome dont les blocs proviennent d'édifices en lien avec le temple d'Apollon précédent [59], dans l'élévation d'autres bâtiments

Acharnes. Les fouilles liées à la construction de nouvelles lignes du métro athénien ont dégagé les fondations du temple d'Athéna Pallénis à la station Stavros et M. Korrès a émis I'hypothèse que le temple d'Arès se serait d'abord dressé sur ces fondations et aurait donc été un temple d'Athéna (KorRes 1999).

[54] LIPPOLIS 2001.

[55] QUANTIN 2007, p. 188-196.

[56] MORETTI 1993, p. 14-17.

[57] Nous avons présenté, D. Laroche et moi, une communication sur le sujet le 4 février 2019 à l'Association des Études Grecques qui fera I'objet d'un résumé dans REG 132 (2019), p. XIII-XIV.

[58] LA Coste-MesseliÈre 1946.

[59] ]ACQUEMIN \& LAROCHE 2017, p. 131 et fig. 1 p. 132 . 


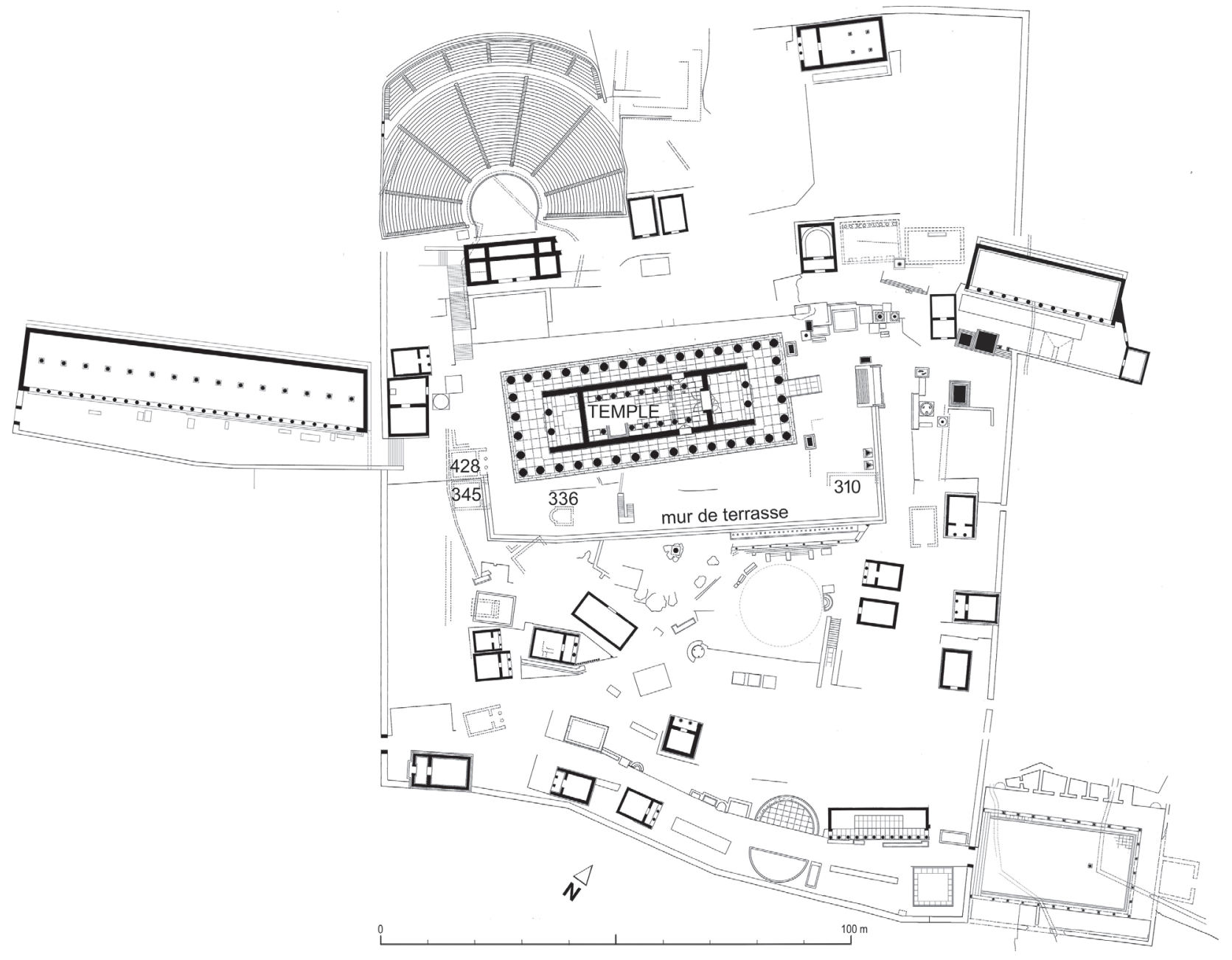

ou dans des fondations : le trésor des Sicyoniens conserve ainsi les éléments d'une tholos en poros et d'un monoptère comportant des métopes sculptées [60]. Parmi ces monuments qui furent détruits par l'implantation de la grande terrasse, certains furent reconstruits : ainsi le trésor SD 345 qui fut coupé par le retour occidental du mur fut reconstruit un peu plus haut, sur la fondation $S D$ 428. Une fondation imposante, supposant une cella de $9 \mathrm{~m}$ sur $11 \mathrm{~m}$ (SD 10 fig. 2) [61], se trouvait en avant du temple d'Apollon. Même si la restitution de sa façade est encore incertaine, cet édifice n'était pas un simple trésor. Son emplacement suggère un

[60] LAROCHE \& NENNA 1990.

[61] Cette fondation a fait I'objet d'études rapides : Courby 19131927 , p. $185-186$ et fig. 154 et 156 ; AMANDRY 1981, p. 679.
A Figure 1 : plan restitué du sanctuaire d'Apollon - DAO D. Laroche, 2018 revu 2019.

$\checkmark$ Figure 2 : intérieur de la terrasse au sud du temple : mur nord et retour ouest de SD 310 - cliché A. Jacquemin 2013.

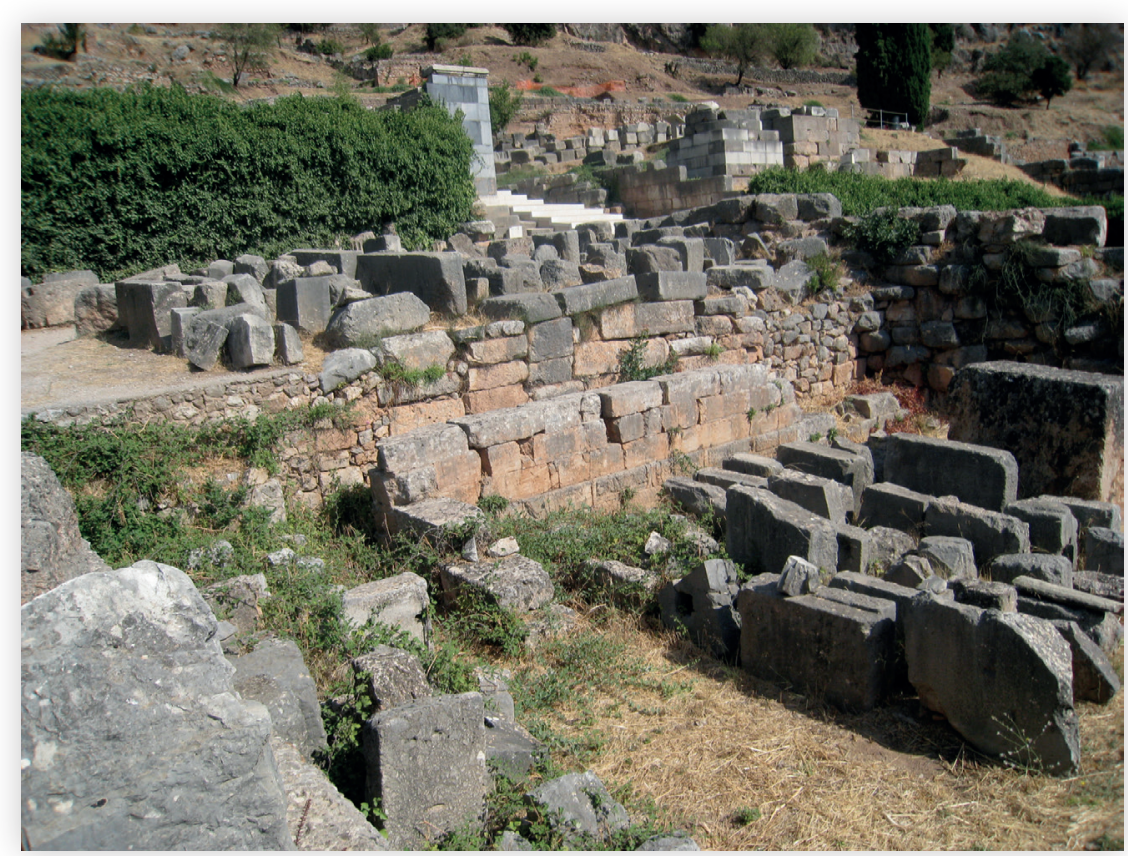




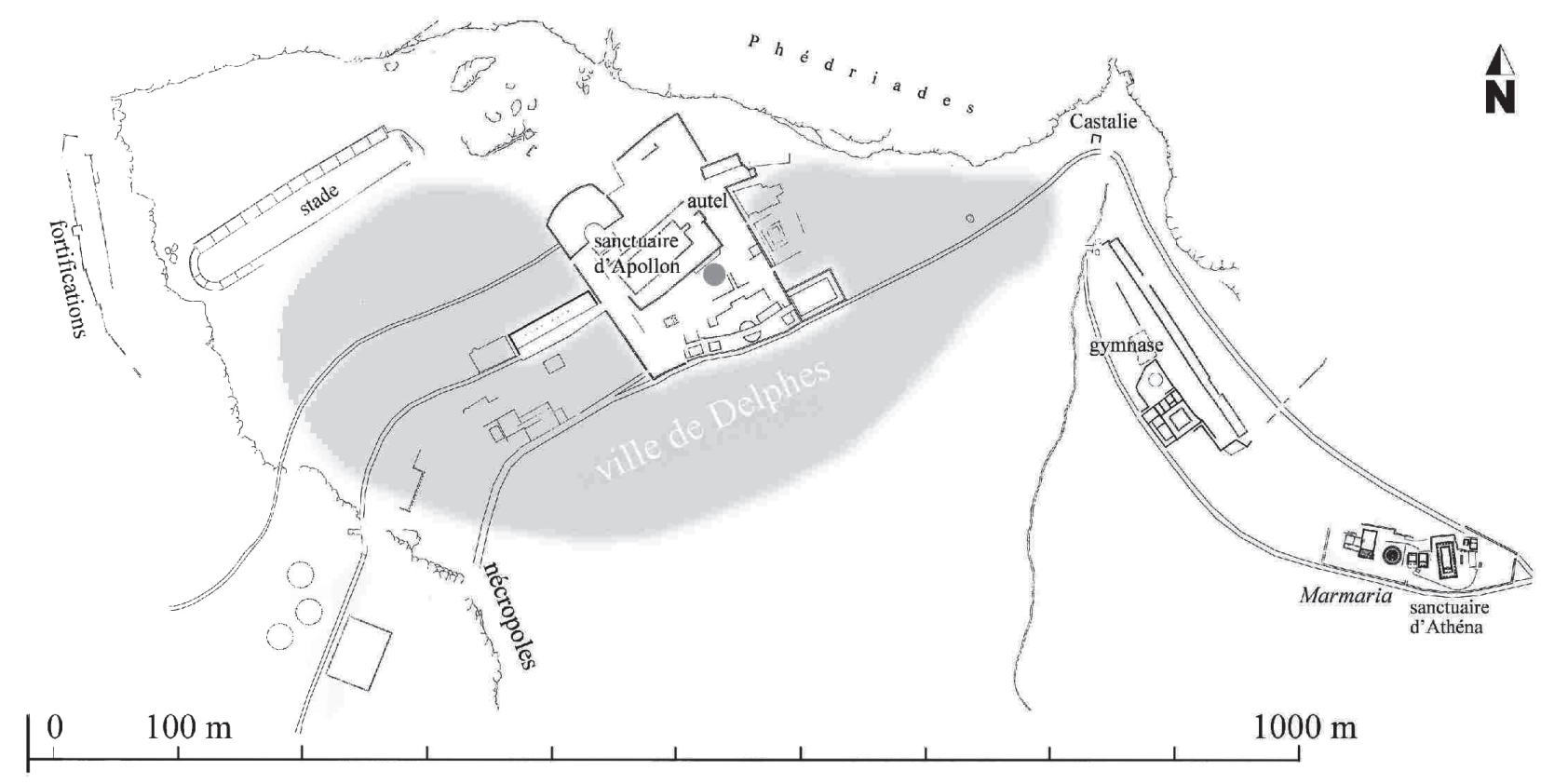

Figure 4 : plan restitué de la terrasse de la Marmariá - DAO D. Laroche, 2015 revu 2019.

lien étroit avec le culte d'Apollon et I'on pourrait en faire le premier temple d'Athéna Pronaia où l'épiclèse aurait eu tout son sens, comme il l'avait au Ptoion ou à I'Isménaion thébain, où Athéna se tenait aussi devant Apollon. À l'époque classique, le sanctuaire de la déesse se trouvait sur la terrasse au sud-est que les Modernes désignent sous le nom de la Marmariá (fig. 3). Or il est singulier de noter que si Hérodote donne à la déesse une épiclèse topique, Démosthène lui attribue une épiclèse morale (Пpovoía « prévoyante », « Providence ») dont il prétend qu'elle est fort répandue et que sa pertinence à Delphes est justifiée par Apollon «qui, comme dieu et devin, sait ce qui est le meilleur » [62]. Le développement de Démosthène montre que l'authentique épiclèse delphique n'est plus comprise.

La fouille de la terrasse de la Marmariá (fig. 4) a mis au jour cinq, puis six fondations, alors que

[62] Hérodote, I, 92 ; VIII, 37 et 39 ; Démosthène, Contre Aristogeiton I, 34.

[63] D. Laroche a calculé que sur les 30 solutions mathématiquement possibles - à la différence de la tradition érudite unanime pour conclure que Pausanias énumère les édifices d'est en ouest, il s'est prononcé pour une présentation d'ouest en est et dans son calcul il intègre les deux hypothèses - seules deux sont à exclure, celles qui identifient le temple d'Athéna Pronaia avec la tholos, car cet édifice a un pronaos, ce qui n'est pas le cas de la tholos.

[64] DeMANGEL 1926.

[65] Voir le rapport dans DAUX 1957, p. 708-709.
Pausanias mentionne quatre vaoi, ce qui a donné naissance à l'abondante littérature des « énigmes de Marmaria » qui cherche quel édifice Pausanias a omis et pourquoi [63]. Dans sa synthèse topographique, R. Demangel concluait à une fréquentation du lieu à fins cultuelles dès l'époque mycénienne, à la suite de sa découverte d'un lot de 175 figurines en phi et en psi au sud des autels et imaginait une continuité de cultes féminins sur cette terrasse [64]. Trente ans après, les fouilles complémentaires de L. Lerat [65] ont montré que ces trouvailles résultaient d'un ensevelissement ultérieur, sans rapport avec une occupation d'époque mycénienne et pouvaient être rapprochées de dépôts d'autels « géométriques » découverts en 1956. À la suite de ce constat, il faut reconnaître qu'il n'existe aucun vestige en place antérieur à la construction du temple d'Athéna à la fin du vi ${ }^{\mathrm{e}}$ siècle, ce qui conduit à I'hypothèse d'un transfert de cultes dans la seconde moitié du siècle, lié à la décision de construire pour Apollon un temple plus grand qui nécessitait une vaste terrasse. Le lieu choisi, de l'autre côté du ravin de Castalie, était alors « péri-urbain », mais il offrait un espace important. Il a fallu transformer ce qui était, selon L. Lerat, «le point de rassemblement des rocs » tombés des Phédriades, un lieu à « l'aspect chaotique » en une terrasse où construire des édifices. Les interstices entre les rochers furent remplis des déchets de sacrifices (cendres et os calcinés), des offrandes obsolètes du sanctuaire originel. Il y eut, 


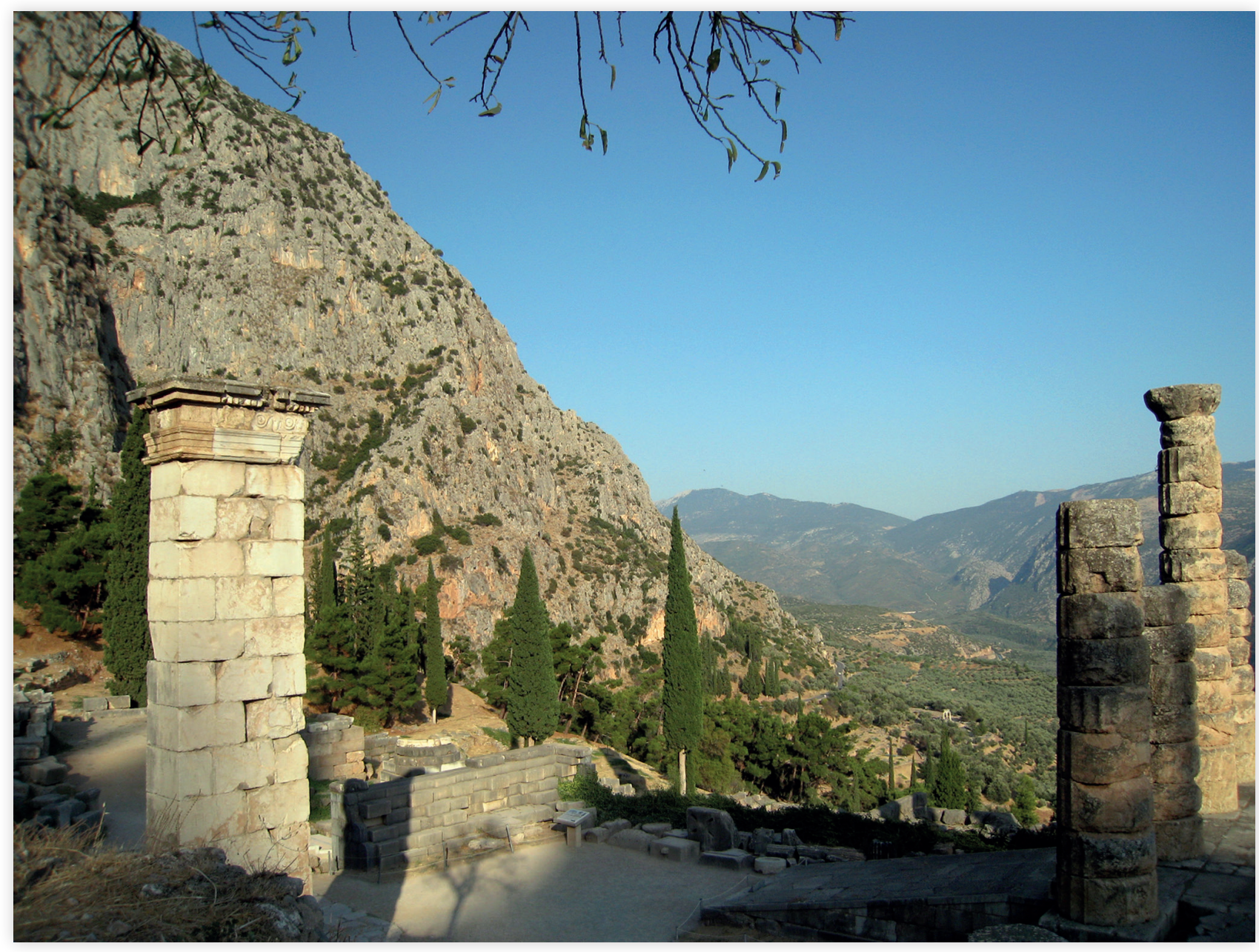

Figure 5

La terrasse de la Marmariá vue du nord-est du temple d’Apollon - cliché A. Jacquemin, 2013.

semble-t-il, des regroupements plus significatifs à certains points, près des autels à l'est [66], près du bâtiment en calcaire élevé au Iv ${ }^{e}$ siècle. Le déplacement de certaines déesses du sanctuaire du haut à celui du bas (fig. 3) s'est accompagné du dépôt

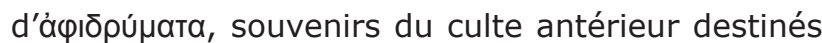
à fonder les nouveaux sanctuaires. Il convient de noter que si le déplacement se fit sur une certaine distance, la terrasse qui accueillit le sanctuaire d'Athéna était visible du temple d'Apollon (fig. 5) et que le sanctuaire pythien se voyait du temple d'Athéna (fig. 6).

Lors de la fouille du sanctuaire d'Apollon, P. Perdrizet avait été très sensible à la « terre noire » mêlée de

[66] Là où furent trouvées les figurines mycéniennes. La structure à l'ouest, près du bâtiment en calcaire, avait été interprétée comme une tholos mycénienne : DEMANGEL 1926, p. 101-102.

[67] KYRIELEIS 2006, p. 27-28.

[68] KYRIELEIS 2006, p. 42-55. cendres, d'os calcinés, de tessons et de fragments de bronze. Il pensait à ce que les fouilleurs avaient trouvé à Olympie, à ces terres si riches en petits bronzes qui avaient permis à A. Furtwängler de construire sa typologie. Les fouilles récentes de $\mathrm{H}$. Kyrieleis à Olympie ont redonné leur importance à cette couche noire («die schwarze Schicht ») [67]. Si le premier centre du sanctuaire est bien là où fut établi à l'époque classique le Pélopeion, l'extension des terres noires rejoint l'autel de cendres, établissant ainsi le lien entre le premier autel et le second autel de Zeus [68]. De la sorte, à Olympie comme à Delphes, les restes des rituels avaient sanctifié l'agrandissement du sanctuaire par l'épandage de terres que le dépôt des restes sacrificiels et d'offrandes avait sacralisées.

La documentation aussi bien textuelle qu'archéologique montre l'importance de la filiation dans le cas des sanctuaires. Il semble même qu'il soit impossible de fonder un culte ex nihilo : les mythes relatifs à des statues apportées par des héros ou des héroïnes dont plusieurs sanctuaires 
pouvaient se targuer de disposer de la relique authentique [69], ou à des statues mystérieusement apparues, tombées du ciel ou rejetées par la mer [70], signifient qu'il y a toujours une origine. Les

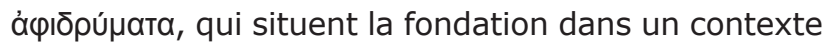
purement humain, présentent la garantie divine par le biais des restes sacrificiels. L'épandage de terres mêlées à des cendres, des os et des offrandes anciennes n'était pas un geste anodin : il permettait certes d'aplanir des surfaces, de faciliter ainsi l'implantation de constructions, mais il transmettait une mémoire sacrée. À Delphes par exemple, il conviendrait de prêter plus d'attention aux secteurs où la fouille a mis au jour ces terres mêlées de vestiges d'actes sacrés, de les cartographier afin de voir si elles ne permettraient pas de suivre une extension du sanctuaire vers le nord. Déplacer un lieu de culte, étendre un sanctuaire demandaient une sanction divine obtenue auprès d'un oracle, mais aussi une sacralisation par contact du lieu avec des objets qui fussent déjà devenus ípá.

[69] Comme la statue d'Artémis apportée de Tauride par Iphigénie à Brauron (Pausanias, I, 33, 1) dont I'original se trouverait en fait à Sparte dans le sanctuaire d'Artémis Orthia (Pausanias, III, 16, 7-8)

[70] Le Dionysos de Méthymna en est un bon exemple : Pausanias, X, 19, 3.

Figure 6 : le sanctuaire d'Apollon vu du temple d'Athéna - cliché A. Jacquemin, 2018.

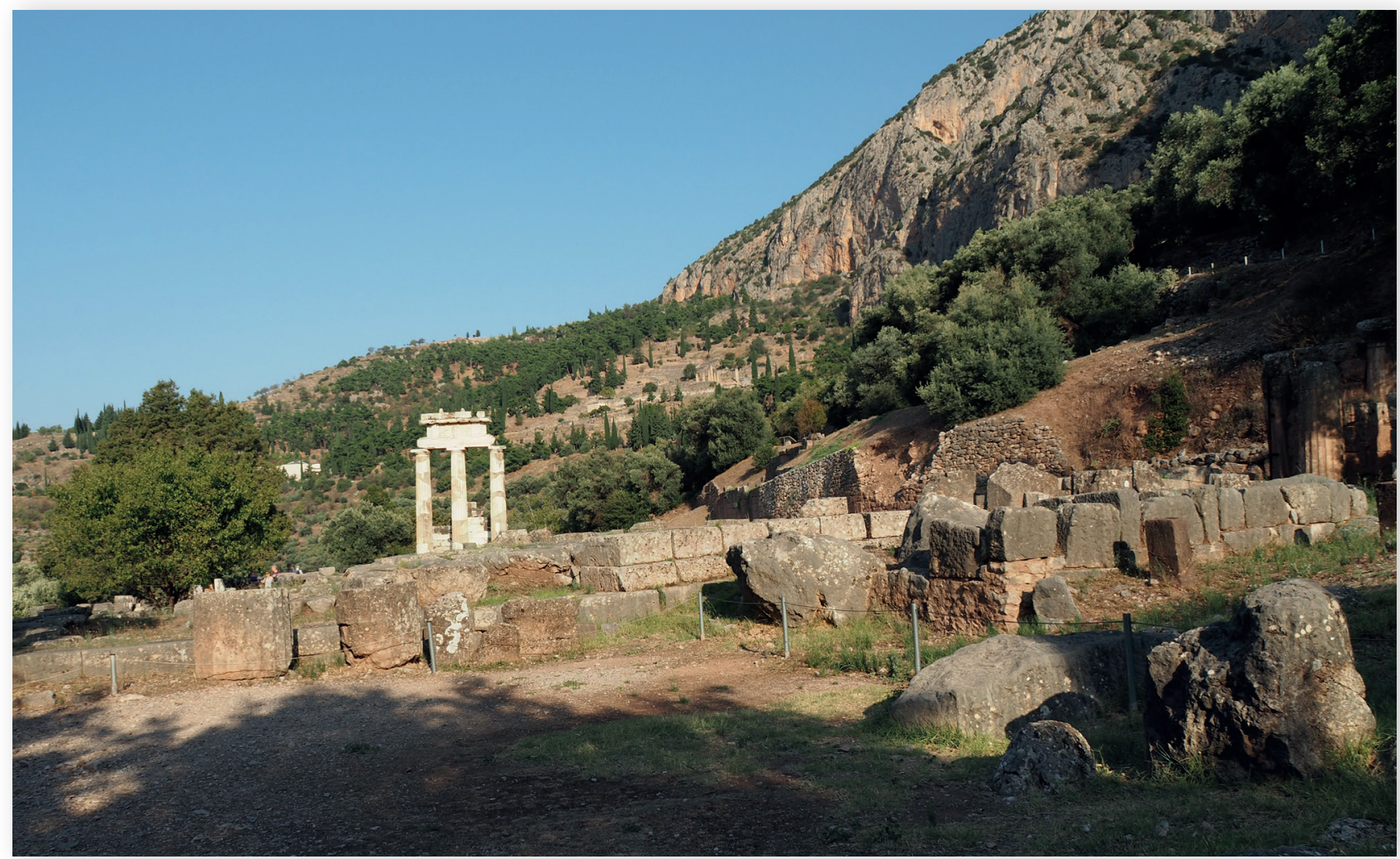

BIBLIOGRAPHIE

Agusta-Boularot, Sandrine, Huber, Sandrine \& VAN Andriga, William (éd.), 2017, Quand naissent les dieux. Fondation des sanctuaires antiques : motivations, agents, lieux, Rome (Collection de l'École française de Rome, 534).

Altheim, Franz \& Stieht, Ruth, 1965, « Die Seleukidinschrift aus Failaka », Klio 46, p. 273-281.

AmANDRY, Pierre, 1981, «Chronique delphique », Bulletin de Correspondance Hellénique 105, p. 673-769.

Ampolo, Carmine, 1994, «Greci d'Occidente, Etruschi, Cartaginesi: Circulazione di beni e di uomini », Magna Grecia Etruschi Fenici, Atti del trentatreesimo convegno di studi sulla magna Grecia, Taranto, 8-13 ottobre 1993, Taranto, p. $223-252$. Arcelin, Patrice, Bats, Michel, Garcia, Dominique, Marchand, Georges \& Schwaller, Martine (éd.), 1995, Sur les pas des Grecs en Occident ... Hommages à André Nickels, Aix-en-Provence (Études Massaliètes 4). 
BoedeKer, Deborah, 2017, «In Search of 'Founding Mothers' », dans Marta Oller, Jordi Pàmias \& Carlos Varias (éd.), Tierra, territorio y poblacíon en la Gregia antigua: aspectos institucionales y míticos, II, Mering, p. 113-132.

Berranger-Auserve, Danièle, 2007, Épire, Illyrie, Macédoine..., Mélanges offerts au professeur Pierre Cabanes, Clermont-Ferrand.

BouvrY, Joëlle, 2012, « Le trésor d'Auriol et les monnayages archaïques de Provence dans les collections du Cabinet des monnaies et médailles de Marseille », dans Muriel Garsson (éd.), Le trésor des Marseillais. 500 av. J.-C., l'éclat de Marseille à Delphes, Paris.

BRULÉ, Pierre (éd.), 2009, La norme en matière religieuse en Grèce ancienne, Liège (Kernos Supplément 21).

Brunel, Jean, 1948, « Marseille et les fugitifs de Phocée », Revue des Études Anciennes 50, 1-2, p. 5-26.

BRUNel, Jean, 1953, «À propos des transferts de cultes : un sens méconnu du mot AФI $\triangle \mathrm{PYMA} »$, Revue de Philologie 27, p. 21-33.

CAMP, John M., 1989, Die Agora von Athen (trad. all. de The Athenian Agora, London, 1986), Mainz.

CASEvitz, Michel, 1985, Le vocabulaire de la colonisation en grec ancien. Étude lexicologique : les familles de ktíl et

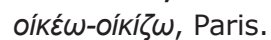

Chantraine, Pierre, 2009, Dictionnaire étymologique de la langue grecque, $2^{\mathrm{e}}$ éd. (1 ${ }^{\text {re }}$ éd. 1968-1980), Paris.

CourbY, Fernand, 1913-1927, Fouilles de Delphes II, La Terrasse du temple.

DauX, Georges, 1957, «Chronique des fouilles 1956 », Bulletin de Correspondance Hellénique 81, p. 644-830.

Demangel, Robert, 1926, Fouilles de Delphes II, Le sanctuaire d'Athéna Pronaia, Topographie du sanctuaire, Paris.

DonAhUE, Alice A, 1988, Xoana and the origines of Greek sculpture, Atlanta Ga.

Donahue, Alice A, 1998, « The Greek image of the Gods. Considerations on Terminology and Methodology », Hephaistos 18, p. 31-45.

Egetmeyer, Markus, 2009, dans Pierre Chantraine, Supplément au Dictionnaire, Chroniques d'étymologie grecque, S.u. i̇̄oúw, p. 1309.

Esch васн, Norbert, 1986, Statuen auf panathenäischen Preisamphoren des 4. Jhs v. Chr., Mainz, p. 58-70.

Estienne, Sylvia, Jaillard, Dominique, Lubtchansky, Natacha \& Pouzadoux, Claude, (éd.), 2008, Image et religion dans I'Antiquité gréco-romaine, Actes du colloque de Rome 11-12 décembre 2003, Naples (Collection du Centre Jean Bérard 28).

GaRSSON, Muriel (éd.), 2012, Le trésor des Marseillais. 500 av. J.-C., l'éclat de Marseille à Delphes, Paris.

GrAS, Michel, 1987, « Le temple de Diane sur l'Aventin », Revue des Études Anciennes 89, p. 47-61.

GrAS, Michel, 1995, «L'arrivée d'immigrés à Marseille au milieu du VI e s. av. J.-C. », dans Patrice Arcelin, Michel Bats, Dominique Garcia, Georges Marchand \& Martine Schwaller (éd.), Sur les pas des Grecs en Occident ... Hommages à André Nickels, Aix-en-Provence (Études Massaliètes 4), p. 363-366.

Greco, Emanuele (éd.), 2002, Gli Achei e l'identità etnica degli Achei d'Occidente. Atti del Convegno Internazionale di Studi, Paestum, 23-25 febbraio 2001, Paestum - Atene (Fondazione Paestum Tekmeria 3).

НАвIChт, Christian, 1970, Gottmenschentum und griechische Städte, 2e éd. (1 ${ }^{\text {re }}$ éd. 1956), München (Zetemata 14).

Hermary, Antoine, Hesnard, Antoinette \& Tréziny, Henri (dir.), 1999, Marseille Grecque. La cité phocéenne (600-49 av. J.-C.), Paris.

Herzog, Rudolf, 1928, Heilige Gesetze von Cos, Berlin (Abhandlungen der Akademie 6).

Hock, Georg, 1905, Griechische Weihegebräuche, Würzburg.

Huysecom-HaXhI, Stéphanie \& Muller, Arthur (éd.), 2015, Figurines grecques en contexte. Présence muette dans le sanctuaire, la tombe et la maison, Lille.

Jacquemin, Anne \& LARoche, Didier, 2017, « Bulletin de la Société française d'Archéologie classique (XLVII, 20152016) », Revue Archéologique, fascicule 1, p. 130-139.

JoNKeES, Jan Hendrik, 1953, « Aristophanes Nubes 401 sq. and the Olympieion », Mnemosyne 10, p. 154-155.

Katsonopoulou, Dora, 2002, « Helike and her Territory in the Light of New Discoveries », dans Emanuele Greco (éd .) Gli Achei e l'identità etnica degli Achei d'Occidente. Atti del Convegno Internazionale di Studi, Paestum, 23-25 febbraio 2001, Paestum - Atene (Fondazione Paestum Tekmeria 3), p. 205-216.

KNOEPfleR, Denis, 1977, « Zur Datierung der Grossen Inschrift aus Tanagra im Louvre », Chiron 7, p. 67-87.

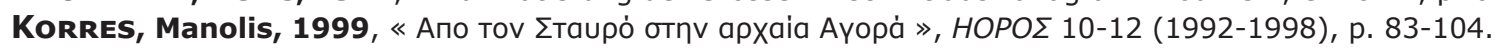

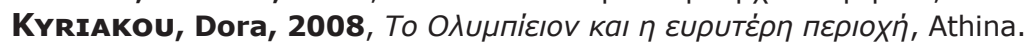

KYRIELeIS, Helmut, 2006, Anfänge und Frühzeit des Heiligtums von Olympia. Die Ausgrabungen am Pelopion 19871996, Berlin - New York (Olympische Forschungen 31).

KYRIELeIS, Helmut, 2011, Olympia. Archäologie eines Heiligtums, Darmstadt - Mainz.

La Coste-Messelière, Pierre, 1946, « Les Alcméonides à Delphes », Bulletin de Correspondance Hellénique 70, p. 271-287.

LAMBRINOUdAKIS, Vassilis, 2002, « Rites de consécration des temples à Naxos », dans Pascale Linant de Bellefonds (éd.), Rites et cultes dans le monde antique, Actes de la table ronde du LIMC à la Villa Kérylos à Beaulieu-sur-Mer les 8 \& 9 juin 2001, Paris, p. 1-19.

LAMbrinoudakIS, Vassilis, 2005, « Consécration. Fondation, Rites », Thesaurus Cultus et Rituum Antiquorum III, Los Angeles, p. 306-346.

LAROChe, Didier \& Nenna, Marie-Dominique, 1990, « Le trésor de Sicyone et ses fondations », Bulletin de Correspondance Hellénique 114, p. 241-284.

LASSERRE, François (édition et traduction), 1966, Strabon, Géographie, livres III et IV, Paris (CUF).

LiNANT De Bellefonds, Pascale (éd.), 2002, Rites et cultes dans le monde antique, Actes de la table ronde du LIMC à la Villa Kérylos à Beaulieu-sur-Mer les 8 \& 9 juin 2001, Paris. 
LIPPolis, Enzo, 2001, « Apollon Patroos, Ares, Zeus Eleutherios. Culti e architettura di Stato ad Atene tra la democrazia a i Macedoni », Annuario della Scuola archeologica italiana di Atene, 76-78 (1998-2000), p. 185-205.

LнôTE, Eric, 2006, Les tablettes oraculaires de Dodone, Paris (Hautes Études du monde gréco-romain 36).

MALKIN, Irad, 1987, Religion and Colonization in ancient Greece, Leiden.

MALKIN, Irad, 1990a, « Missionnaires païens dans la Gaule grecque », dans Irad Malkin (dir.) La France et la Méditerranée. Vingt-sept siècles d'interdépendance, Leiden, p. 42-52.

Malkin Irad (dir.), 1990b, La France et la Méditerranée. Vingt-sept siècles d'interdépendance, Leiden.

MalkIN, Irad (éd.), 1991, «What is an Aphidruma? », Classical Antiquity (California Studies in Classical Antiquity) 10, p. 77-93.

Merer-Brügger, Michael, 2000, Indogermanische Sprachwissenschaft, 7e édition revue et complétée par Matthias Fritz et Manfred Mayrhofer, Berlin - New York.

MigeotTe, Léopold, 1992, Les souscriptions publiques dans les cités grecques, Genève - Québec.

Morel-Deletaille, Myriame 1999, « Mythe, historique et politique : les célébrations du vingt-cinquième anniversaire de la fondation de Marseille », dans Antoine Hermary, Antoinette Hesnard \& Henri Tréziny (dir.), Marseille Grecque. La cité phocéenne (600-49 av. J.-C.), Paris, p. 9-14.

MoretTI, Jean-Charles, 1993, Théâtres d'Argos, Athènes (Sites et Monuments 10).

Oller, Marta, PÀmias, Jordi, VARIAs, Carlos (éd.), 2017, Tierra, territorio y poblacíon en la Gregia antigua : aspectos institucionales y míticos, II, Mering.

Paul, Stéphanie, 2013, Cultes et sanctuaires de l'île de Cos, Liège (Kernos Supplément 28).

Pirenne-Delforge, Vincianne, 2008, « Des marmites pour un méchant petit hermès! ou comment consacrer une statue », dans Sylviane Estienne, Dominique Jaillard, Natacha Lubtchansky \& Claude Pouzadoux (éd.), Image et religion dans I'Antiquité gréco-romaine, Actes du colloque de Rome 11-12 décembre 2003, Naples (Collection du Centre Jean Bérard 28), p. 102-110.

Polignac, François de, 1995, La naissance de la cité grecque, $2^{\mathrm{e}}$ éd. (1 $1^{\mathrm{re}}$ éd. 1984) Paris.

Polignac, François de, 1997, « Mythes et modèles culturels de la colonisation grecque archaïque », dans Mito e Storia in Magna Grecia. Atti del trentaseiesimo convegno di studi sulla Magna Grecia, Taranto 4-7 ottobre 1996, Taranto, p. 167-187.

Prandi, Luisa, 1989, «La rifondazione del "Panionion" e la catastrofe di Elice (373 a.C.) », dans Marta Sordi (éd.), Fenomali naturali e avvenimenti storici nell'antichità, Milano (Contributi dell'Istituto di storia antica 15), p. 43-59.

Prost, Francis, 2009, « Norme et image divine. L'exemple de la "statue d'or" de l'Acropole », dans Pierre Brulé (éd.), La norme en matière religieuse en Grèce ancienne, Liège (Kernos Supplément 21), p. 243-260.

QuANTIN, Séverine \& QuANTIN, François, 2007, « Le déplacement du temple d'Athéna Polias en Chaonie. Remarques sur les "cosidetti" temples voyageurs », dans Danièle Berranger-Auserve (éd.), Épire, Illyrie, Macédoine..., Mélanges offerts au professeur Pierre Cabanes, Clermont-Ferrand, p. 175-196.

REINACH, Théodore, 1899, « Un temple élevé par des femmes à Tanagra », Revue des Études Grecques 12, p. 53-115. ROBERT, Louis, 1965, Hellenica XIII, Paris.

ROBERT, Louis, 1977, « Documents d'Asie mineure. IV Deux inscriptions de Tarse et d'Argos », Bulletin de Correspondance Hellénique 101, p. 89-132.

Rolley, Claude, 1997, Annali di Archeologia e Storia Antica, n.s. N. 4, p. 35-45.

RUDHART, Jean, 2001, «La perception grecque du territoire sacré », Mélanges de l'École française de Rome - Antiquité, 113, p. $175-188$.

SheER, Tanja Susanne, 2000, Die Gottheit und ihr Bild. Untersuchungen zur Funktion griechischer Kultbilder in Religion und Politik, München (Zetemata 105).

SINN, Ulrich, 1985, « Der sog. Tempel D im Heraion von Samos. II Ein archäologischer Befund aus der nachpolykratischen Zeit mit einem Exkurs zum griechischen Bauopfer », Mitteilungen des deutschen archäologischen Instituts, Athenische Abteilung 100, p. 129-158.

SokolowsKI, Franciszek, 1969, Lois sacrées des cités grecques, École française d'Athènes, Paris (Travaux et mémoires 18). SoRDI, Marta (éd.), 1989, Fenomali naturali e avvenimenti storici nell'antichità, Milano (Contributi dell'Istituto di storia antica 15).

UhleNBROCK, Jaimee P., 2015, « Heirlooms, Aphidrumata, and the Foundation of Cyrene », dans Stéphanie HuysecomHaxhi \& Arthur Muller (éd.) Figurines grecques en contexte. Présence muette dans le sanctuaire, la tombe et la maison, Lille, p. 143-156. 